\title{
SOME ASPECTS OF SPRINKLER IRRIGATION IN TROPICAL REGIONS')
}

\author{
J. C. J. MOHRMANN \\ International Institute for Land Reclamation and Improvement
}

\begin{abstract}
SUMMARY
In order to make the best use of the limited area of good soils in the tropics an intensive crop rotation should be aimed at; the fallow periods should be reduced to the minimum; the cultivation of several crops a year will have to be contemplated. But this means that the sowing and harvesting dates are set within narrow limits and that irregularities and imperfections in the climate will have to be corrected. Sprinkler installations may prove extremely useful in order to start sowing or planting even before the commencement of the rainy season, or in order to tide over on the normal sowing dates vacillation in the onset of the rains. When the growing season is postponed to the second half of the rainy period it may be necessary to maintain the soil moisture content at the right level by means of sprinkling during the transition period and the beginning of the dry period. Sprinkling may also be useful for eliminating the troublesome short, dry period occurring irregularly in many areas during the rainy season.

The latter possibility and the shortening of the long dry period are also regarded as important for perennial crops. But in the case of certain crops complete elimination of the long dry period may have a harmful effect.

In the tropics, therefore, sprinkler irrigation is chiefly considered as a supplementary measure. Moreover it is too expensive to apply sprinkler irrigation throughout the dry season provided no special circumstances occur which may justify the lengthy operations of pumping and spraying large amounts of water.

In preparing irrigation projects the choice of system will often depend on the topography, the character of the soil, etc. If the choice is not immediately obvious other possibilities should be studied. A number of pros and cons of sprinkler irrigation as compared with surface irrigation are discussed, emphasis being placed on the special conditions which may occur in the tropics (topography, soil profile, land levelling, drainage of surplus water, erosion, water consumption, rate of application, mobility and flexibility, investment and operating costs, effect of the wind, fertilisation, diseases and parasites).

Owing to the limited capacity of sprinkler installations it is sometimes a difficult matter to calculate what amounts of water should be applied and in which frequency. In particular the spray irrigation schedules for the short dry period and the transition period should be carefully prepared.

The various types of sprinkler installations are mentioned insofar as they are of interest in the tropics.

In conclusion some labour problems are discussed and a suggestion is made for cooperative sprinkling on small native farms.
\end{abstract}

\section{INTRODUCTION}

Sprinkler irrigation is a method of irrigation of which the technique was only developed some twenty years ago. Originally sprinkler irrigation was only applied in horticulture, the necessary equipment being designed and made in lncal workshops. These installations were not very satisfactory inasmuch as too little attention was paid to uniform distribution of the water, while the precipitation rate was often so high as to injure the crop, cause puddling, and have a harmful effect on the structure of the soil. Since however it was discovered that in humid areas where irrigation of agricultural crops was long considered an unnecessary step, water shortages could also occur and inhibit the growth

1) Received for publication January 28, 1959. 
of crops, ingenious installations have been designed which have greatly contributed to the rapid development of sprinkler irrigation. Hence it is a remarkable fact that modern techniques of sprinkler irrigation were not originally developed in arid or semi-arid regions where this might have been expected, seeing that in such regions the application of irrigationwater has always been a traditional and essential feature of agriculture. But the conventional methods of irrigation had become too deeply rooted in these regions to make it an attractive proposition to begin on new and apparently very costly methods. Moreover these regions were usually industrially underdeveloped, with the result that agricultural technique lacked the very important stimulus of industry.

Sprinkler irrigation technique has developed on more or less parallel lines in America and Europe. In the eastern part of the United States it was only being applied to some 39,000 acres in 1939. In 1957 the sprinkled area was about 650.000 acres, viz. a 17 -fold increase in a period of less than twenty years.

From the temperate regions the modern sprinkler irrigation technique has penetrated to the semi-arid and arid regions of North Africa and the western part of the United States where especially since the second world war the sprinkled acreage has been greatly extended. During the past few years sprinkling as a method of supplemental irrigation, has also attracted attention in the tropics, particularly in the savannahs and the forested savannahs surrounding the tropical rain forest in which there are dry periods of shorter or Ionger duration. At the present day sprinkling is being applied in Brazil, the Belgian Congo, Angola, Tanganyika, Kenya and Rhodesia, and in India and Ceylon.

Sprinkler-irrigated crops include coffee, cocoa, tea, tobacco, cotton, sugar cane, bananas and various food crops such as maize, groundnuts, beans and potatoes.

WhAT IS THE USE OF SUPPLEMENTAL IRRIGATION IN THE TROPICS?

It may be questioned whether sprinkler irrigation has any use in regions which in many cases have a very high annual precipitation. Irrigation is indeed a known conception in the tropical and very densely populated regions of Asia, but this chiefly relates to the wet cultivation of rice and as a complementary to certain second crops. But up to few years ago irrigation was an almost unknown conception in tropical Africa and South America. During the rainy period there was, in fact, more than enough water available for the cultivation of a seasonal crop. During the dry period certain crops such as beans and potatoes were cultivated on the storage water built up in the soil during the period of precipitation. As regards perennial crops, a good many are accustomed to an annual period of rest more or less coinciding with the dry period and in which there is little or no need of waterconsumption. During this period of rest supplying water may even produce the wrong effect. Thus on certain soils in Atrica less favourable results were obtained with the irrigation of citrus during the dry season as a result of excessive vegetative development and for the same reason it may be doubted whether there is any use in irrigating bananas during this season. 
In addition to the fact that there are a large number of crops which, technically speaking, are not strictly in need of water supply, there are the economic drawbacks. In general a sceptical view is taken of the possible return on expensive irrigation systems and, moreover, one of the main problems is the lack of technical knowledge of the population. True the same objection also applies to mechanisation, but it a is simpler matter to convince people that tractors and agricultural machinery will have to offset the enormous lack of manpower in Atrican and South American countries than that irrigation, with its heavy demands on labour should now be begun. In the present stage of development the political and economic problem facing agriculture in these regions is primarily increase in production per manpower unit on the one hand and expansion of the agricultural acreage on the other. In the case of a good many individual estates however there can, in practice, be no further question of increasing the available acreage. In fact, it is becoming increasingly difficult to renew existing concessions and practically no new concessions are being granted. Consequently if the estates are to raise their productivity, the only solution is to intensify the production area they already possess. Native agriculture is faced with similar difficulties. Owing to the rapid growth of population the cycle in which arable farming and fallowing alternate is becoming ever shorter, little room being left for the natural regeneration of the soil. An increasing need is being felt of more intensive cultivation of the existing agricultural acreage and a rotation system which would enable the length of the fallow period to be reduced to a minimum and possibly entirely eliminated in the future. Plans are even being worked out for cultivating two or three crops a year in districts where shifting cultivation used to be a common feature, farmyard and green manure being introduced in order to maintain the level of soil fertility. As will be explained below a regular water supply is often essential to such an intensive type of agriculture.

\section{The PLACE OF SUPPLEMENTAL IRRIGATION}

Let us now consider how we can specify in greater detail the place which should be occupied by irrigation in the tropics for the purpose of increasing productivity and intensifying agriculture. To this end we must revert to the climatic character of these regions. It was mentioned earlier that although in most regions the total annual precipitation is very high, tropical regions, with the exception of the equatorial rain forest, are characterised by a dry period in which there is hardly any rainfall. This period is of fairly constant duration in each district, viz. two to six months. In addition to this long dry period, a shorter dry period, varying from 1 to 2 weeks to 1 to 2 months, occurs in certain climatic zones in the course of the rainy season; as a result of this interruption the rainy season may be separated into a first and second rainy period. A feature of the short dry period is the irregularity with which it occurs and great annual variation in its duration, unlike the long dry season which is much more settled, although its beginning and end cannot always be forecast with certainty.

In connection with the water supply, the crops may be subdivided into the tollowing groups:

- Crops whose growing season mainly coincides with the first rainy period; 
- Crops whose growing season mainly coincides with the second rainy period;

- Crops whose growing season is spread over the greater part of the entire rainy season, viz. the first and second rainy period including the short dry period;

- Crops whose growing season mainly occurs in the long dry period;

- Perennial crops.

When the crop sequence is so adjusted that successive crops are always interrupted by a shorter or longer fallow period, no great difficulties will usually be anticipated as regards the natural supply of water. The crop is not sown until the first rains have fallen; growth then results from the precipitation which maintains the soil moisture content at the right level. But should it be desired to make optimum use of the area covered by good soils the fallow periods will have to disappear and the target to be set will be the cultivation of two or three crops a year. But such an intensive sequence of crops makes it necessary to fix the sowing and harvesting dates within very narrow limits. It will not always be possible to wait until a rainy period begins before deciding to sow the crop. In particular, it is when the first rains fail that steps will have to be taken to ensure a supply of water. It may also happen that owing to the time schedule, crops subsequently cultivated in the dry period have to be sown later than usual when the soil will already be dried up to a great extent.

It is obvious that such an ambitious programme of crop sequence will have little chance of success if one cannot intervene at critical periods in order to ensure a steady water supply. This implies that the irrigation scheme should have a wide degree of flexibility with the minimum possible restriction as to time and place.

In the case of perennial crops other problems occur with respect to the water supply. The growth of many of these crops is actually inhibited by the occurrence of the short dry period, particularly when they are grown on light textured soils (and the upward movement of capillary moisture has no effect). If the short dry period continues for more than a few weeks, crops growing on heavier textured soils may also have to contend with a shortage of water. It is true that these soils usually have a high moisture-holding capacity, but part of the moisture is so strongly attached to the soil particles that the plants derive little or no benefit from it. Moreover it is often not sufficiently realised that once these soils have dried up, the moisture supply in the root zone available to plants is reestablished at a much slower rate than in case of the lighter soils. Whereas the latter are saturated to field capacity to a considerable depth even during the first rains, the heavier soils are still only moistened in the top layer from which this moisture evaporates with ease and rapidity.

The long dry period, or drought season also merits closer examination. Certain perennial crops will actually benefit if water can be regularly supplied during this season. But one should proceed with particular caution, seeing that the physiological cycle of a large number of perennial crops is adapted to an annual period of rest in which practically no moisture absorption appears to be required. If the soil is saturated with water during this period this may unexpectedly result in such harmful reactions as excessive vegetative growth to the detriment of fruit setting and yield, the occurrence 
of diseases and parasites, leaf drop, etc. There is still very little known about the duration of this passive period; is is certainly wrong, however, to assume that this period is always co-extensive with the duration of the drought season. It is quite possible that a few applications of irrigation water may have a positive etfect at the beginning or end of the long dry season.

Certain seasonal crops such as beans and potatoes which are only cultivated during the dry period develop entirely on the available storage water. A few applications of irrigation water at the beginning of the growing period may often have a very stimulating effect, particularly on soils with a somewhat smaller moisture-holding capacity. But in this case also irrigation should be stopped in time so as not to produce any harmful effect. After the fruit setting these crops only absorb a slight amount of moisture so that it is usually unnecessary to irrigate after the flowering period.

It is sometimes possible to introduce an entirely new crop during the dry season by means of artificial water supply. For instance, in an experimental polder laid down in Rhodesia, wheat and barley are irrigated both by furrow and sprinkler irrigation. Owing to the high rate of evapotranspiration and the long duration of the dry season very large amounts of water have to be pumped up, so that it becomes an extremely expensive proposition to irrigate these crops by sprinkling. But since the price level is high these costs are acceptable from the point of view of profitability.

To summarise, it can be stated that irrigation in the tropics may be particularly important as a supplementary measure for increasing the production level of perennial crops and that this measure will often be indispensable if it is intended to undertake an intensive rotation of crops.

\section{SPRINKLER IRRIGATION AND DIVISION OF LABOUR}

Reference should be made to the manner in which sprinkler irrigation equipment is used in planting out sugar cane in the Lower Congo region at Moerbeeke. The problem confronting this estate is that planting period and peak working season considerably overlap during the first rainy period. This obliges the staff to divide their attentions simultaneously between planting, harvesting and manufacture, and a large labour force is required for carrying out the various operations in the field and factory. Attempts were already made before the second world war to achieve a better division of labour and higher level of production by means of surface irrigation, but this proved a failure owing to the very irregular topography of the land. Land levelling was considered not to be economically feasable. Owing to surface erosion much of the irrigated area soon lost its fertility and has still not been entirely restored today, twenty years after the experiment.

With the aid of a mobile sprinkler equipment of relatively small extent it is now possible to start planting out well before the commencement of the rainy season, thus being practically ready before the actual working season is in full swing. The irregular topography is no longer proving an obstacle. The resultant labour-saving alone has enabled the entire sprinkler installation to be written off in a single year.

Labout probelms are also becoming serious in Angola. The leading sugar estate is drawing up plans for mechanical harvesting. This requires level fields, 
however, so that the deep irrigation furrows should make way for sprinkler installations.

\section{THE CHOICE OF IRRIGATION SYSTEM}

The above-mentioned example of Moerbeeke already shows that the choice of irrigation system is of great importance. Hence the first question which arises in drafting a project is whether to apply irrigation according to the conventional methods, viz. surface irrigation, or by the more mechanised method of supplying water by sprinkler irrigation. In certain instances the choice is not a difficult one; topography, soil conditions, etc. inhibit sometimes an economic method of surface irrigation. On the other hand there is little point in introducing sprinkler irrigation if the topography is specially adapted to surface irrigation, or if the population has gained wide experience in the conventional form of irrigation.

But very often the choice is not so simple. A number of aspects have to be weighed up against one another and in difficult cases this may mean that a decision can only be made after two ore more fully worked-out plans have been studied. This decision will be greatly influenced by practical and economic considerations. Thus in an experimental polder in Rhodesia on heavy margalite soils, the feasibilities of furrow and sprinkler irrigation are being compared with the assistance of the Netherlands Land Development and Reclamation Society. The structural condition of the soil renders gravity irrigation particularly difficult in this area, but on the other hand sprinkling is more hindered by the very great effect of the wind.

In some large-scale irrigation projects a combination of sprinkler and gravity irrigation may be considered. We may take as an example the irrigation of a valley and as much as possible of the foothills surrounding the valley. Formerly, when irrigators tried to cover the largest possible area with gravity water, it was drawn off from the river as high as possible, occasionally by very expensive and complex works and conducted with the slightest possible gradient via syphons and aqueducts along the foothills, following a line conforming to the often irregular topography of the land. In a modern irrigation project it is also possible to adopt another method when circumstances permit, since pumps, pipe lines and sprinklers are available, making it easy to reach the area positioned higher up than the irrigation canal, at any rate provided energy can be supplied sufficiently cheap. To this end the basic design is so adapted that the main canal has a minimum of expensive works and the simplest possible line. Accordingly the lower-lying land will primarily be considered for gravitity irrigation and the higher land for sprinkler irrigation.

The general advantages of sprinkler irrigation to surface irrigation may be summarised as follows :

- The topography of the land is of minor importance in sprinkler irrigation, whereas it is of prime importance in surface irrigation. Practically all lands which are unsuitable for surface irrigation or can only be adapted to it at great expense and trouble, may be sprinkled with comparative ease. This is the case, for instance, in:

- very uneven lands which it would be too costly to level; 


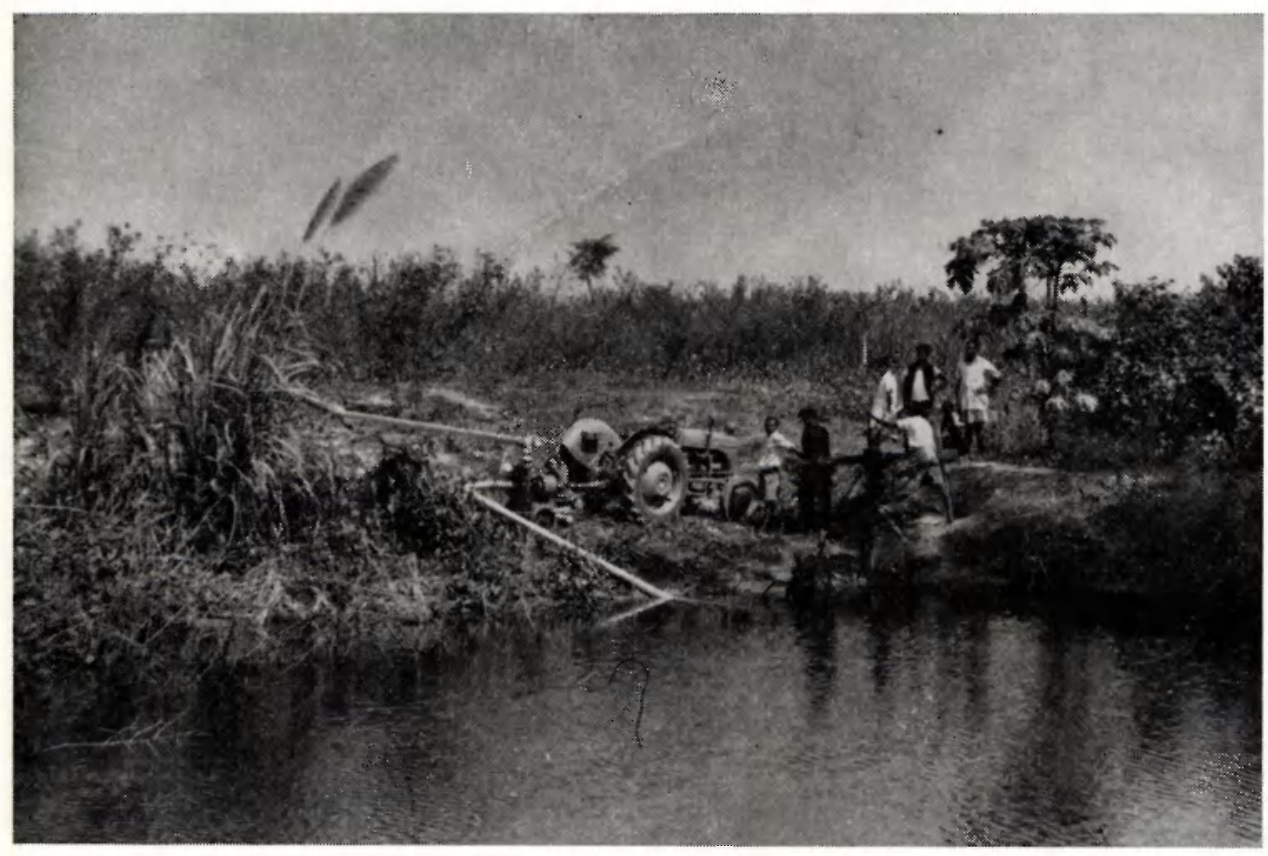

Fig. 1 Pumping irRigation water from a Canal by means of a tractor.

- steep slopes where surface irrigation without adequate terracing would give rise to the use of large amounts of irrigation water and involve a risk of soil erosion. It will obviously also be necessary to safeguard against erosion on such slopes if sprinkler irrigation is applied, but only with a view to a high rate of the natural precipitation, not as a result of excessive irrigationwater.

- The expensive levelling of the land, as well as the construction and maintanance of a large number of canals, levees, plots, basins, furrows and corrugations (maintenance being particularly expensive in the tropics) can be dispensed with in sprinkler irrigation projects. Such earthconstructions often constitute a very grave hindrance to mechanised agriculture. The much smaller number of earthconstructions with sprinkler irrigation means that less cultivable land is lost, viz. about 1 to $5 \%$ of the area which can be irrigated.

- Excessive irrigation water no longer occurs and does not therefore have to be drawn off; this may be a considerable saving on the drainage system, but, of course, only insofar as this system has no part in the drainage of surplus precipitation water.

- In sprinkling projects the soil is less sensitive to erosion and deterioration of the structure than in the case of surface irrigation. There is no need to upset the soil by levelling, and this is a factor of primary importance in tropical regions in particular where the fertile topsoil is usually only very shallow. In a good sprinkler irrigation project no water will flow along the surface thus eliminating beforehand any danger of erosion or lowland puddling caused by irrigation water running off or rising ground water. 
The latter problems in particular, which are due to insufficient levelling, inexpert distribution and excessive use of irrigation water, are inherent to inadequately prepared and poorly functioning irrigation projects. In areas where the population is still unfamiliar with irrigation practices, it is important that the application of sprinkler irrigation should afford as little opportunity as possible for the destructive use of water.

- Sprinkler irrigation enables the most economic possible use to be made of the irrigation water available. Water losses caused by deep percolation can be minimised, ensuring in practice a saving of 10 to $25 \%$ of the water supplied to the fields. Sprinkler irrigation is the method of choice where the soil is highly pervious (in which case it prevents percolation losses) or if the soil is exceptionally impermeable (when it prevents runoff).

- Sprinkler irrigation is also very valuable for newly-sown fields which may benefit from frequent, small applications of water. In the conventional method of irrigation it is very difficult to distribute the available water in this way. In surface irrigation there is also the danger of seeds and young plants being entrained or inundated by the flowing water, or of being too deeply covered by the shifting soil.

- The mobility and flexibility of sprinkler installations permits their temporary use for young plantations which only require incidental applications by way of injection. There is no need to construct costly irrigation works for a temporary use.

- In certain cases sprinkler irrigation may mean labour-saving as compared to other methods of irrigation, particularly when a permanent installation is employed.

- Sprinkler irrigation ensures better aeration of the soil than irrigation methods in which water temporarily settles on the land or flows over it. It is also anticipated that the cleansing of dusty foliage will be a good secondary effect of sprinkling when it is applied during the dry season.

- Artificial manure gives a better result with sprinkler irrigation than with other methods of irrigation because leaching or washing away can be prevented. Soil impoverishment, a phenomenon occurring in surface irrigation with water poor in nutrient elements, is seen to a much less extent in sprinkler irrigation since deep percolation is reduced to a minimum. Moreover the irrigation water can be mixed comporatively easily with waste products (e.g. from sugar factories), with finely divided compost or farmyard manure, or with fertiliser.

The chief disadvantages of sprinkler irrigation are the following:

- The high operating costs resulting from the use of electricity or fuel, this being particularly disadvantageous if electricity has to be transported over long distances or fuel has to be imported; if sprinkling is continued throughout the dry season vast amounts of water have to be pumped up and sprayed, and this becomes extremely expensive.

- The fairly high initial cost which has to be written off over a comparatively short period (10 to 15 years).

- The bad distribution of water in a high wind.

- The delicate operations of moving lines and sprinklers in the crop while the soil is still soaked in moisture. 


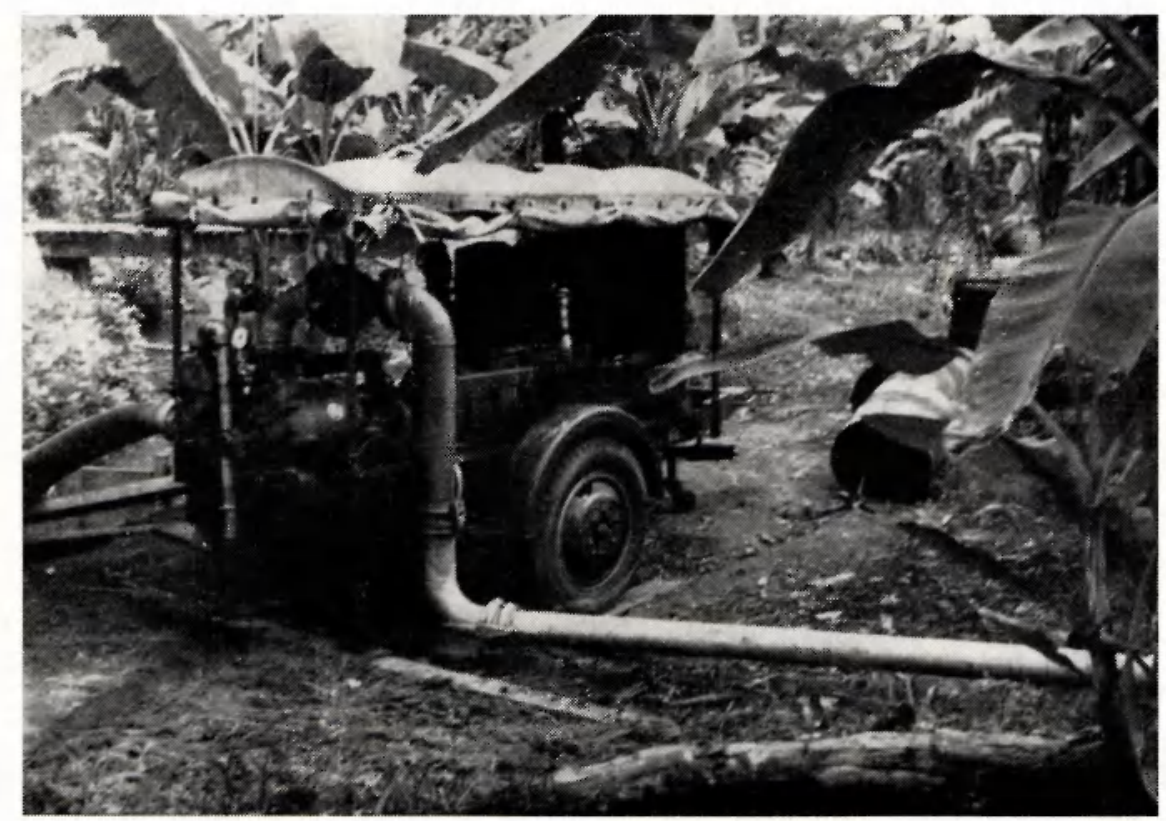

Fig. 2 Pumping installation In Bananas plantation in Belgian-Conco.

- The staff who should be skilled in handling the equipment and capable of carrying out sprinkler irrigation according to plan; this is a problem which is often not so readily solved in underdeveloped tropical regions.

- Diseases and insect pests may sometimes be encouraged during and after sprinkling by the increase in atmospheric humidity and there also is a possibility that sprinkler irrigation creates a more favourable environment for certain physiological diseases; thus it was found in the Belgian Congo that the danger of blossom-end rot in tomatoes was increased by sprinkling during the dry season.

- Sprinkling when the sun is at its height may cause burning of the foliage of certain sensitive crops; in such a case it is better not to apply sprinkler irrigation in the middle of the day but during the morning and evening, and if possible at night-time also, althouguh this may be attended by drawbacks in practice.

We shall now consider briefly certain climatic and agro-hydrological factors which should be taken into account in drawing up sprinkler irrigation projects, particularly in tropical regions.

\section{Consumptive USE OF THE CROPS}

The process in which water absorbed by vegetation from the soil moisture supply is transpired and in which moisture also evaporates direct from the topsoil is termed evapotranspiration. In order to determine how much water should be applied to the crops it is essential to know the extent of the evapotranspiration during the various stages of development of the crops.

The investigation into the potential evapotranspiration is in full swing also in some tropical regions. In the Belgian Congo, for example, one or more lysimeters, 
in which the evapotranspiration from a sward is examined daily, have been installed in a large number of INEAC climatological stations scattered throughout the country.

Lysimeters have been installed at Yamgambi and M'Vuazi for the purpose of examining the evapotranspiration from crops along with the evapotranspiration from a sward or the evaporation from a waterpan and an attempt is made to determine correlation figures. By means of these correlation figures and the regional waterpan or sward observations it is hoped to obtain a practical means of gauging the water needs of the irrigated crops in the various districts of the Congo ${ }^{2}$ ).

In other tropical areas there is still no such research for practical ends, and recourse has to be made to experience gained in similar climatic zones. But such data are very difficult to obtain and highly uncertain. A better approximation is obtained with the use of a method of calculation. We can choose between a method based principally on physical laws developed by PENMAN in England, and methods based entirely on empirically determined correlations. Although Penman's formula has the advantage of being soundest from the scientific point of view, the disadvantage is that a fairly large number of meteorological data have to be known and that the method has not yet been sufficiently tried out in the tropics. Nevertheless excellent correlations have already been obtained in the Belgian Congo between the calculations according to Penman and the evapotranspiration measured in the lysimeters. Empirical methods such as those of Thorntwatte, Blaine-Criddle or Haude and correlations with Piche evaporimeters have proved less satisfactory. The reason is that all these formulas were drawn up for other climatic zones than the tropics. But attention should be drawn to the method recently developed in Paris by TURC who compiled empirical formulas from the data provided by a large number of lysimeters in various climatic zones and the waterbalances of over 300 river basin areas scattered throughout the world. This method is very promising for practical use and compared to the lysimeter observations has also given excellent results in Africa.

The DETERMINATION OF THE RATE AND FREQUENCY OF IRRIGATION

When the amount of water required by the crops is known over monthly periods or over ten-day periods and provided this amount is not covered by the precipitation it is necessary to determine the frequency and intensity of irrigation required to eliminate the precipitation deficiency. For this purpose it is necessary to know the amount of readily available water which can be stored in the soil. It should be stated that in general the storage capacity for readily available water is less in the tropics than in the temperate zones, the reasons being as follows:

- Heavy textured soils with a high moisture-holding capacity are scarce, and where they occur the percentage of water strongly bound to the soil is often very high on account of the nature and structure of the soil.

2) It should be mentioned that the "Mission Ressources Aquifères" at Ruanda Urundi has obtained particularly good results with a network of petrol containers ingeniously converted into simple evapotranspiration meters. 


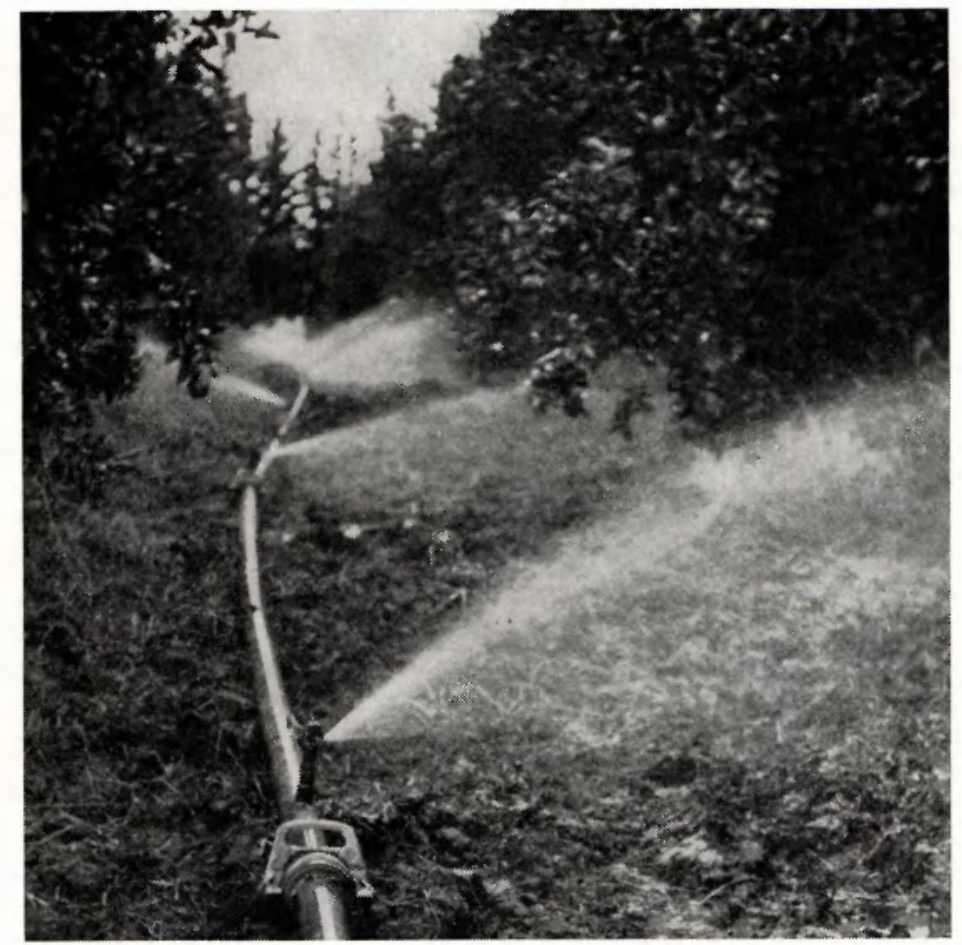

Fig. 3 Low-angle sprinkler system in an orange plantation in Marokro.

- The humus content, which is important for the moisture retention of light soils, is usually low. Moreover the humus-rich topsoil, where it occurs, is shallow.

- Owing to the structural state which is often poor at a shallow depth the root zone is confined to shallow surface layers.

Owing to such unfavourable conditions the readily absorbable moisture does not generally exceed 20 to $50 \mathrm{~mm}$. By means of these figures and those of the consumptive use (evapotranspiration) it is possible to calculuate the irrigation frequency. The sprinkler installation is then so designed that if the frequency is calculated to be, say, ten days, $1 / 10$ of the area can be supplied with water every day. The amount of water supplied should be sufficient to cover the evapotranspiration during this period.

Such a relatively rigid schedule has certain drawbacks which, in the tropics in particular, may be revealed by the special use to which the installation is often desired to be put. The following cases may be distinguished:

- sprinkling at the beginning of the dry season,

- sprinkling during the short dry period,

- sprinkling at the end of the dry season.

THE TIME TO START SPRINKLING

In the above cases it is difficult to determine the exact time at which sprinkling should be begun and to institute such a transitional scheme that 
there is no failure in the water supply for the crops, always bearing in mind the relatively limited capacity of the installation.

In practice too often one starts irrigating at the commencement of the dry season when the crop shows signs of suffering from drought; sometimes it is not applied until superficial observation shows that the root zone is drying up. It is then usually too late because the capacity of the sprinkler installation is insufficient to irrigate in a short space of time the entire area suffering from a shortage of water. In fact it would require a very expensive installation which could fully supply the entire area with water in a short time. One just cannot afford to use for only a few days in each irrigation period the very extensive installation which would then be required, and allow it to lie unused during the remainder of the period.

Hence in order to avoid the risk that irrigation of the last sections of the area can only be undertaken when the crop has suffered extensively from continued drying of the soil, one should take into account the limited capacity of the installation when starting up sprinkling. It should also be borne in mind that once the last section of the area has dried severely, the usual application to which the sprinkler installation is adjusted, is incapable of wetting the soil to a sufficient depth. Even with later applications in accordance with the normal scheme, this section of the area would still only be superficially moistened and the lowest part of the root mass would be in bonedry soil throughout the dry season.

One should therefore start much earlier and draw up such a programme of sprinkling that the last section of the land is irrigated before the soil moisture at this point has exceeded the maximum permissible degree of depletion. To achieve this end it is best to start irrigation as soon as possible after the last heavy shower of rain, adjusting the applications to the water requirements which are relatively slight at first but soon steadily increase. Since it is usually possible to estimate with accuracy when the rainy season will change to drought, it is fairly easy to determine the date on which sprinkling should be begun.

The situation is different if it is desired to apply sprinkler irrigation during the short dry period. In many districts both the beginning and the duration of this period are extremely irregular. Hence it is practically impossible to judge which rain will be the last one of the first rainy period. To avoid the risk of starting to irrigate when one is still in the middle of the rainy period, it is best to adjust the applications to the depletion of the soil moisture. This should be estimated or measured with the greatest possible accuracy. But this degree of wetness should be much higher than that to which the soil is allowed to dry in accordance with the usual programme of sprinkling which has been adjusted to the amount of readily available water in the soil if one is again to avoid the risk of not irrigating the last section of the land until the critical soil moisture depletion has already been passed. But the consequence is that the applications are smaller and the irrigation is more frequent than that prescribed by the general scheme indicated in the previous paragraph. This possibility of adaptation should be taken into account when drawing up the sprinkling scheme.

Should it be desired to employ the sprinkler installation for sowing or 


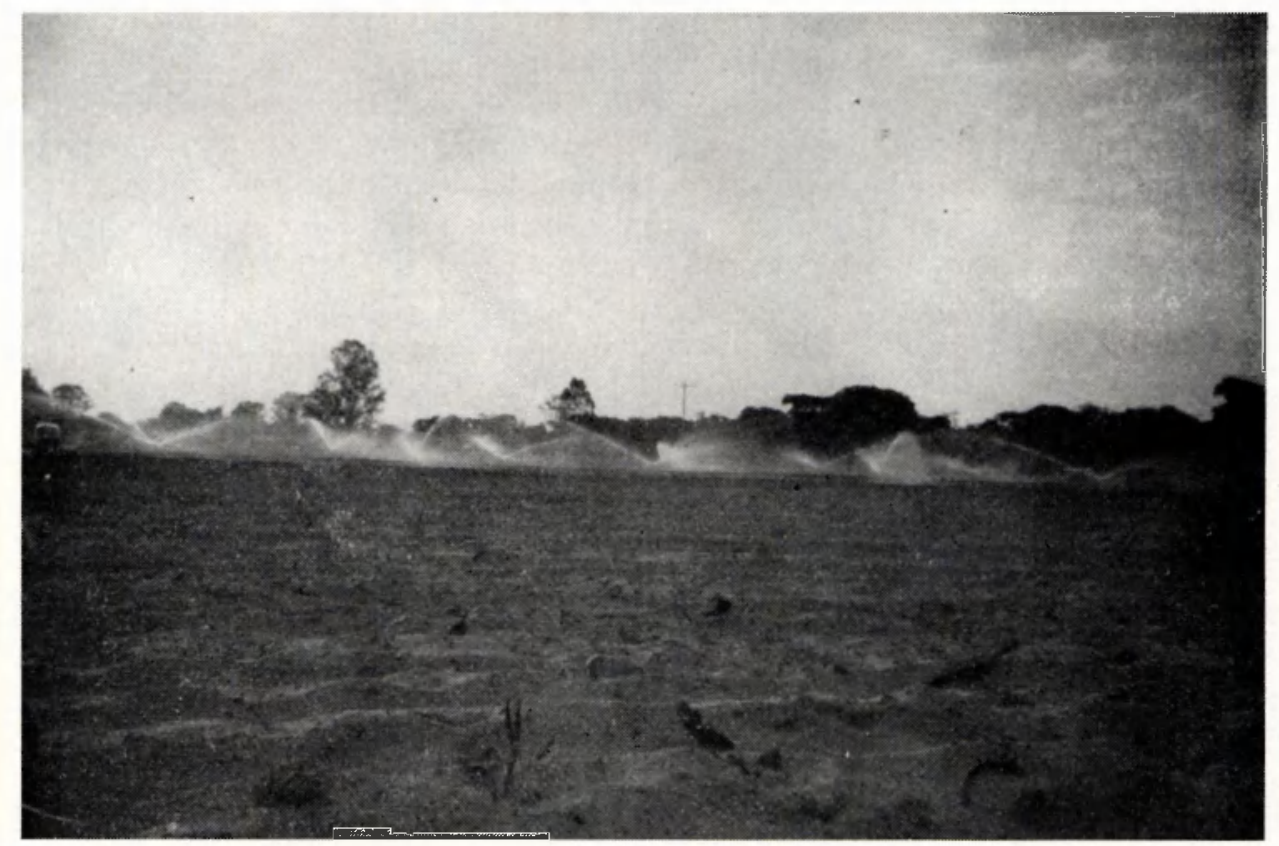

Fig. 4 Preparing a seed-bed at the end of the dry season By spininling.

planting during the dry season, viz. before the rains begin two important factors should be taken into account:

- The soil is completely dry at the moment irrigation is begun. Consequently much more water has to be given than would be the case in a normal sprinkling scheme in which action is taken as soon as the soil has only partially dried up.

- Newly sown crops and young plantations require frequent applications with small amounts of water.

It should be noticed that it is often thought best to entirely saturate the soil with water before starting to plant or sow. But this is only possible if it is wanted to plant or sow a much smaller area than that on which the installation is normally based, and provided irrigation is begun well before the actual date of sowing or planting.

One should be aware of the fact that by doing this the soil will be moistened to a depth to which no plant roots can penetrate for the time being.

In most cases, however, this method has its drawbacks inasmuch as the farmer will always wish to sow or plant the greatest possible area with the equipment available, hence a plan should be drawn up by which an early start is made in watering the soil, while taking care to ensure that when it is required to begin sowing the soil is only saturated to field capacity to a certain depth (a slight depth for sowing and somewhat deeper for planting). By means of small but frequent applications of water the moisture content in this layer of soil should be maintained at the right level, the moistened zone 
being slightly deepened by each irrigation so as to keep ahead of the growth of the root system. After some time it will be possible to adopt a normal irrigation schedule and this is continued until the rainy season sets in ${ }^{3}$ ).

The technical princtiples of Sprinkler irRigation aNd the labour problem

In sprinkler irrigation the irrigation water is drawn from rivers, canals, reservoirs, lakes or the ground water by means of pumping installations after which it is led through pipelines under pressure and finally distributed over the land as evenly as possible via sprinklers.

In mountainous regions it is sometimes possible to develop enough pressure for the sprinklers by abstracting the water from streams or reservoirs at some point above the irrigated land. The consequent saving in pumping plant and fuel is a very great advantage, seeing that power is the most important factor determining cost.

The sprinkler irrigation equipment may be classified as follows:

- entirely permanent installations in which the sprinklers are attached via risers to permanent lines usually installed underground;

- fully portable installations consisting of portable pipes held together by "quick couplers";

- semi-portable installations in which the lateral pipes consist of quickcoupling portable pipes attached to a permanent main line by means of hydrants.

Permanent installations require least work but their initial cost is high because the permanent lines cover the entire irrigation system and therefore have to be much longer than is the case in portable installations in which another part of the system can always be operated with the same set of quickcoupling portable pipes. Although permanent pipes are cheaper than quickcoupling portable pipes, the total investment required for a permanent installation is heavy owing to the immobilisation of a considerable part of the material. Hitherto these permanent installations have only been employed in very intensive agriculture or in horticulture.

In Europe semi-portable installations are consideredi to be the most economic design as they enable the economic optimum to be reached under present conditions. The permanent part is limited to the mainline, the portable laterals are regularly shifted by workers engaged on the farms.

In tropical Africa fairly general preference has hitherto been given to portable installations. Although the labour required for the frequent shifting is scarce and expensive, there are two reasons why the portable design is preferred:

- It is desired to be restricted as little as possible to a particular field or group of fields, seeing that a considerable part of irrigation is in the form of "irrigation d'appoint" in which the entire installation is shifted from one group of fields to another which is sometimes very distant.

3) Examples of the way in which these translation schedules are drawn up are given in the August number of the Bulletin Agricole du Congo Belge (Vol. XLIX, 1958, no. 4, pp. 877-922). 


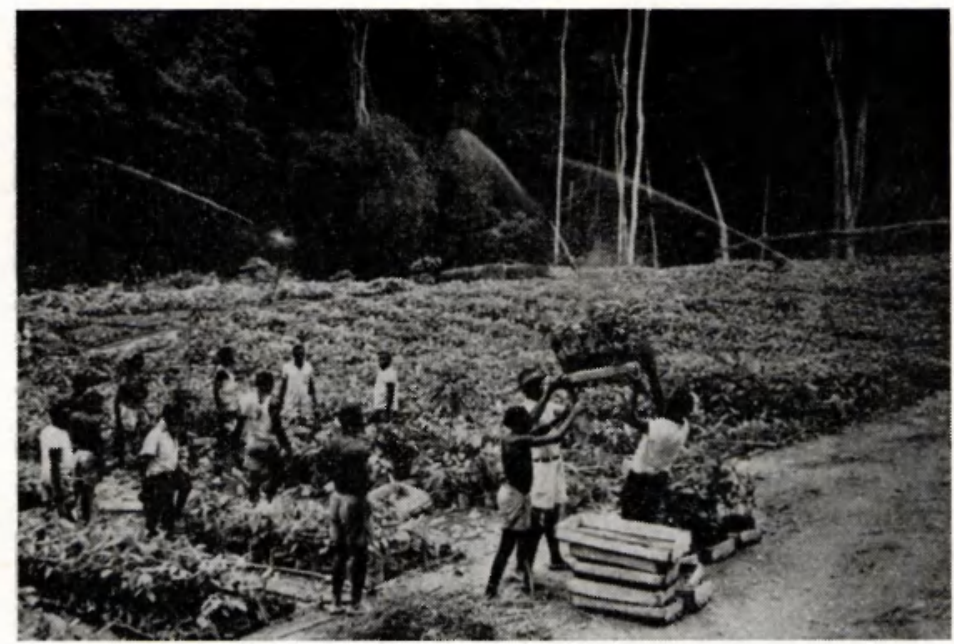

Fig. 5 Sprinkling of a cocoa-nursery iv Belgian-Congo.

- Staff has to be trained in handling the equipment and carrying out the sprinkling schedule; it should devote the whole of its attention to this responsible work. Under present conditions in Africa it is impossible to adopt the European solution in which the farmer himself moves the lines and sprinklers in between other activities. If therefore a group of workmen have to be appointed for this task they should be given a full-time job as far as possible, in which case the frequent shifting of a large number of lines is no longer any drawback.

There are a great many different types of sprinkler installations. A distinction is made between rotating sprinklers giving a continuous jet, rotating sprinklers giving an intermittent jet; oscillating lines with spray nipples; perforated lines; lines with hammer-action sprinkler nozzles; square sprinklers. The type mainly used in agriculture is the rotating sprinkler in which each sprinkler irrigates a circular area or a section thereof. In order to irrigate a given area it is necessary for these circles to overlap. The aim is to distribute the water as uniformly as possible, this depending on the distribution pattern of the type of sprinkler at different pressures, the spacing between sprinklers and the layout (triangular or square). The smallest sprinklers irrigate a circle having a radius of approximately 12 metres at a pressure of about $1.5 \mathrm{~kg}$ per sq. $\mathrm{cm}$ at the sprinkler nozzle. On the other hand, there are also sprinklers which deliver the water a distance of 75 metres when operated at $10 \mathrm{~kg}$ per sq. $\mathrm{cm}$ nozzle pressure. It is difficult to give a general classification as the characteristics of the various types overlap, but the following classification may be recommended on practical grounds:

Sprinkling with a precipitation rate from 1.5 to $5 \mathrm{~mm}$ per hour (in a layout with optimum overlapping) the pressure at the nozzle being low to medium (1.0 to $4.5 \mathrm{~kg}$ per sq. $\mathrm{cm}$ ).

Sprinkling with a precipitation rate of from 5 to $25 \mathrm{~mm}$ per hour; the pressure at the nozzle is medium to high $(3.0$ to $10.0 \mathrm{~kg}$ per sq. $\mathrm{cm})$. 
In Europe slow sprinkling is preferred, in which the number of settings can be reduced to two or three every twenty-four hours. This leads to a considerable labour-saving and better division of labour on the farm, particularly during peak periods. Moreover the land can be irrigated at night without sleep having to be disturbed in order to move the installation. Slow sprinkling has other advantages we will not dwell upon here, merely mentioning that in this system a larger number of sprinklers are used, but of a smaller and less expensive type than in the case of rapid sprinkling.

In tropical Africa, however, the situation is different. Slow sprinkling is undesirable when the aim is to provide continuous work for the team in charge of irrigation operations. On the other hand, in rapid sprinkling the hours of darkness are not utilised owing to the great risk of manoeuvring in the crop with lines and sprinklers during the night, and the fact that it is often impossible to induce staff to do night-work in the field. The latter is, of course, a more or less local phenomenon. In any case, the decision whether to apply slow or rapid sprinkler irrigation does not lie so much in the economic plane as in the plane of what is practicable and desirable.

\section{SPRINKLER IRRIGATION ON SMALL NATIVE FARMS}

Hitherto we have only discussed the type of sprinkler irrigation which is undertaken by a team specially trained for the purpose. Such a method is obviously necessary for sprinkling on estates. But what is the situation when it is required to apply sprinkler irrigation on small native farms? Little experience has been gained in this direction, on the one hand because the investment and operating costs of sprinkler irrigation are high and on the other hand' because the population is very slow to grasp modern agricultural techniques.

But here and there small-scale experiments are being undertaken, usually still in or near research centres.

It is very easy to understand why on practical and economic grounds individual application of sprinkler irrigation on small native farms is out of the question for the time being. But should the desirability of sprinkling become urgent it might be possible to seek a solution on a co-operative basis, as is already being done for mechanical tillage. The individual farmer would then no longer be obliged to deal with water and expensive equipment but the sprinkler irrigation project could be entrusted to a team properly trained for the purpose. To ensure its smooth functioning such a co-operative should be on a well-established basis and strictly regulated. This does not alter the fact that the personal responsibility and powers of judgment of the cultivators in question should be developed. Hence in determining how the water is to be used a voluntary basis is extremely important, and increasing account should be taken of the views of the land users themselves when assessing the need to sprinkle crops at any given time. All this implies that co-operative sprinkling should be characterised by a great deal of adaptability in both the general pattern and the day-to-day management. 